\title{
Study on learning strategies and the problems affecting the performance of English listening
}

\author{
Zhao Hui Min ${ }^{1, \text { a }}$ \\ ${ }^{1}$ Bohai university, Jinzhou, 121013 China \\ ahmzhao2008@163.com
}

Keywords: English listening; performance; factor analysis; learning strategies; methods.

\begin{abstract}
Listening and speaking skills have always been a difficult problem for Chinese students, and it is also the bottleneck of improving the quality of English teaching. It is very necessary to actively and effectively helping students improve their listening and speaking skills, especially the ability of listening. In this article, we analyze the problems that affect the performance of English listening and propose specific strategies to improve the ability of English listening for students.
\end{abstract}

\section{Introduction}

English listening plays a very important role in English learning. People often say that listening, speaking, reading and writing are the basic skills of English. Listening is put to the first position, which fully proves the importance of listening. However, for many years, the traditional English teaching has concentrated on English examination, which leads to a lot of students can not use English to communicate and exchange. At the same time, with the deepening of the reform of university English 46 class examination, English listening proportion is also increasing, which brings more challenges to participate in the 46 exam candidates, English listening has become a puzzle for Chinese College English learning. Therefore, more and more attention has been paid to English listening. In colleges and universities, many listening courses are opened in the curriculum, and students also pay more attention to listening practice. However, college students generally have problems in English listening. College students usually spend much time in English listening while the effect of learning is not as good as expected. In this article, the author analyzes the problems that affecting the performance of English listening and proposes some strategies to improve it[1].

\section{The importance of listening in English learning}

\section{Listening is an important part of the initial stage of language learning.}

Real hearing is the use of a large amount of information stored in the brain to analyze, judge and understand the information received by the ear, so that the brain to further acquire new knowledge. According to linguists, the use of language in everyday social life is "listening" 45\%, "said" "30\%", "read" "16\%", "write" 9\%. Can "hear" an important role in language communication; the famous American successful master Blaine Tracy (Brian Tracy) in his classic 21 Secrets of Self-made Millionaire said, through a sound learning materials is the revolution of learning style in twenty-first Century, "listen" to obtain information of human hearing is remarkable significance; to obtain oral material, solve the dumb English starting line, it is one of the important guarantee to obtain high scores in English.

\section{Listening is the most important form of language communication.}

Language is a tool for people to exchange ideas; it is the formation of a sound after the text. We learn English without listening and speaking, and listening is the most basic means of language communication. Only by understanding the meaning of other people can express their wishes, and ultimately achieve the purpose of communication with others. 


\section{Listening is the initial form of the perception of language information.}

From the point of view of psychology, all speech activities are based on their own speech perception. Tests show that the amount of information that people get through the ear canal is far more than the visual. Listening is a kind of language information input, the information after the processing of the brain, will have to say that the output of language information.

\section{Factors affecting the level of listening}

\section{Associated factors.}

In English the same meaning, if two words adjacent to the former consonants ending, the vowels at the beginning, will naturally be the first sound last note is located in front of the word and the next word together, constitute a syllable, which is even read. Read after the words sound more fluent and smooth. But for the listener, it may cause a certain degree of difficulty; affect the listener's understanding of the meaning of the sentence. For example, in the When the rates are down, [its] and rates back end [a:] tone sandhog into [tsar:], naturally difficult to cause the sound recognition. It can be inferred that the more read a sentence, sound recognition more difficult [2].

\section{Phonetic assimilation factors.}

Assimilation in English is caused by the difficulty of learning English listening. The so-called "assimilation", which is the two adjacent sounds, affects each other, and sometimes becomes the same or similar sound; sometimes the combination produces a new sound. In English, there are many kinds of assimilation, which can be divided into three kinds according to the influence of the influence. From the previous sound effects after a sound phenomenon called progressive assimilation, a word like individual, [d]: [n] affected assimilation in front of it to [n], so it [individjun]. The former one is called the inverse assimilation by the latter one. News [nju: s] is combined with paper to form a compound noun newspaper, which is read as [nju: zpeiper], because the [s] is influenced by the post tone $[\mathrm{p}]$ to [z]. Two near the sound interaction merging into a new phoneme is mutual assimilation, in English [so t d] [j] in neighboring sound integration. Mutual assimilation can occur in the word.

\section{Intonation factors.}

Chinese is a tone language, each word has a tone, and this tone plays an important role in the difference or change of meaning. The English words are not in the tone, but the English sentences are intonation. The tone accent is a word in the pitch degree of preparation and change of iambic. There are five basic types of intonation in English: the falling tone, the rising tone, rising tone, falling rising tone, and tone. Each tone can express the speaker's attitude or tone. The word meaning of a sentence and the meaning of intonation can be regarded as complete meaning. The same English sentence, intonation, meaning will be different, and sometimes even a thousand miles. For example: thinks we ought to get the A: Mr.Smith money in hand first.B: Who? If B use the rising of "Who", said not hear each other talk in a part of the request, repeat the part. An answer should be Smith Mr. But in the following sentence, like to have someone to say a word at the beginning to welcome the group.B: Who? A: We'd? If the B says: "Who" with falling tone, its meaning is to ask each other, who want to welcome speech at the opening. A: it's the name of the person who should say the welcome word. In a word, speech is the basis of listening comprehension. Chinese students only learn English pronunciation and intonation, to understand the basic knowledge of phonetics and pronunciation phenomenon, to master the rules of English language flow and the function of intonation, to further improve their listening and speaking ability [3].

\section{Weak reading factor.}

In English, some words have a weak form of reading. Such as he, me, and she, pronouns them, US, we, you, him, a, an, the qualifier, her, his, our, some, your, and, as, but connectors, so, auxiliary verbs, modal verbs must, shall, will, would, could etc. at, for, of, prepositions, to, etc. These words have one, two or more than two forms of pronunciation. In the case of none stressed, they are usually in the form 
of a weak reading; the pronunciation is often made them very light, or very vague, but also shortens their pronunciation time. For example: A: Did Henry paint the whole house himself He had it? B: painted, because he doesn't like climbing ladders. Q: What do we learn from the conversation Henry does not? A) Like the color. B Someone painted the house.) Else C) There was no ladder in the house. D Henry painted the house himself. Option) B is correct, but there are also many listeners due to had it painted it to read and understand the influence of weak, he had painted, thus made the wrong choice D) option. So in rapid speech, due to the weak and read some phonemes is lost, will give the listening comprehension caused by deviation. But sometimes, if a person is weak, or if the speaker is to emphasize these words, the speaker is going to use their strong form of reading. For example, in the sentence will go to the concert. She, if the speaker would like to express is "she", rather than someone else to go to the concert, will use the strength of the she form. Because these words can be read as well as weak, if the English learners do not know enough about their different forms of pronunciation, it is very likely that they are not clear or difficult to understand what the speaker is saying.

\section{Strategies for improving listening comprehension}

\section{Focus on cultural background factors.}

From the perspective of the relationship between language and culture, language is a part of culture, and plays an important role in culture. Language is the cornerstone of culture - there is no language, there is culture; from another perspective, the language and the culture of the impact, reflecting the culture. It can be said that language reflects the characteristics of a nation; it contains not only the historical and cultural background of the nation, but also contains the nation's views on life, life style and way of thinking. Language and culture interact with each other; understanding the language must understand the culture, the understanding of the culture must understand the language. In listening comprehension, the listener gets information to try to put these captured information with its own cultural background knowledge related, so as to better understand the speaker's expression content or geographical implication. If students hear "Chinese lunar new year related content", naturally reminiscent of a series of content associated with Spring Festival, after listening to will of course handy materials; on the other hand, do not know the "Santa Claus" is the person who is difficult to associate with Christmas related content. Only when the listening material is combined with the background knowledge, passive listening is the active listening, so that the students can take the initiative in their own initiative and take the initiative in solving the problem [4].

\section{Pay attention to grammatical factors.}

Grammatical factors reflected in grammatical structure, language materials in unfamiliar and complex Chinese sentence structure and contrary to the logical expression on students' auditory cognitive interference such as: you should have finished it yesterday. should have+ if the students understand the grammatical structure of the past participle, they can understand the meaning of the sentence is: you should have done yesterday, but you did not complete implies the accused if the students do not understand the grammar phenomenon, it is hard to figure out the meaning of them and in some parts of the complement is omitted in the practice of such a sentence: Do you Mind if I ask you to practice speaking English with me? The underlined part requires students to fill in the blanks, but most of the students have to write speaking speak, the reason is practice after the students to make the language Law phenomenon does not understand.

\section{Strengthen the reading training.}

Monterey International Graduate School is the United States translation and translation of the top professional schools, the following ten is the Monterey school to the new students: more than 1 reading, in particular, to read a foreign language work. Read high quality newspapers every day (such as "New York Times", "Wall Street journal", etc.); adhere to at least one year. Read high quality magazines (such as "economists", etc.), each page should be read. Read a foreign language work on topics of interest to you. Read other high quality materials that help broaden the horizon. 2 pay more 
attention to the current events in the TV and radio. Don't just listen to news stories, to analyze the news. Keep pace with the times and keep pace with current events. Record the news programs and interviews in order to review. 3 strengthen your knowledge of economics, history, law, international politics, and science, and understand the basic concepts and principles. Strengthen your knowledge in a particular field (preferably in a technical field, such as computer).4 live in a country in which you are learning a foreign language for some time. Stay with or maintain interaction with native speakers of your native language. In some foreign language courses, such as macro economics, political science, and so on, rather than simple language courses). Work in an environment that requires a higher level of foreign language. 5 improve your writing and research skills. Take challenging composition courses (not just creative writing class, but in journalism, technical writing, of course), so you can be familiar with the "news", "united state system" and "legal" style of writing. Copy foreign language textbooks and journals. Write down the grammar points that are not used or easy to make mistakes, and try to grasp them. Do more exercises correcting. 6 improve your public speaking skills. Take a rigorous lecture course. Practice writing and speaking in front of others, both in native language and in a foreign language. 7 hone your analytical skills. Practice speaking to sum up the central idea of the speech that is heard. Write a summary of the news report. Practice explaining difficult articles. Practice explaining complicated concepts. The background of research resources (including library network, etc.) more than seven kinds of reading, when added in culture is to practice their language thinking, this is especially important in learning a foreign language.

\section{Strengthen grammar learning.}

In the study, although many English learners realize the importance of learning grammar, but could not find effective learning methods and learning strategies, but let the grammar get scorched by the flames, open writing mistakes, thinking and expression of Chinese and English, a far cry from. In fact, English grammar is relatively simple, standardized. As long as the establishment of grammatical awareness, in accordance with the correct approach to learning, we must be able to master English grammar. The authors from the following five aspects to talk about how to learn grammar. The tradition of learning English grammar on the basis of understanding the way: listing large grammar rules to understand from real life restrictions and fetters, actual sentences and texts, this method not only can't afford to arouse initiative learning interest and learning, it is difficult to cultivate their ability to use the language of communication. As a result, grammar learning should be related to language and context. To truly understand the learning grammar, not rote. I began learning English, the teacher emphasized the role of different participle and gerund in sentences, many students can memorize: word attributes, adverbial, complement, predicative; verb noun can be used as attributive, subject, object, and predicative. Even if it is often confused. In fact, the word is equivalent to the adjective, adjective can act as the composition, the basic word can act as a word, the verb is equivalent to the noun, the noun can act as the composition, and the basic can act as a verb. It is easy to understand why the verb noun can act as the subject and object. However, note that not to understand the grammar and syntax rules follow the end. English learners in the learning process should be good at the active observation, induction, and summary of grammar rules, do not rely entirely on the teacher or book to explain. The study shows that the learner's own summary of the grammatical rules is better than the one that comes from the book to school. Learners should be good at learning from mistakes. Mistakes in English learning is inevitable, learners do not be afraid to make mistakes, to boldly use English; on the other hand, should pay attention to correct the mistakes, learn from the mistakes. Finding errors and correcting errors is one of the purposes of doing English exercises. For the teacher's homework, we must be careful to see. The teacher's correction is not clear, be sure to ask the teacher or students. In oral communication, can't completely disregard the syntax, but also because they are afraid of making mistakes in grammar and dare not speak. Completely disregard of grammar, may make the habit of grammatical errors, and later want to change also changed. For fear of making mistakes and not opening or too much in the expression of self correction will affect the smooth progress of communication[5]. 


\begin{abstract}
Summary
Listening is the most important form of communication in English language; it is the initial form of the information of perception, and it is an important link in the initial stage of language learning. The factors that affect the level are pronunciation, vocabulary, grammar, cultural background, five factors of emotion. We can from the focus on learning and using phonetic knowledge; strengthen the reading training; strengthen grammar learning; strengthen the cultural background of the study; improve the five aspects of psychological quality targeted to strengthen the English listening level. In short, to really master a foreign language, so that it plays a role in international communication, we must understand it from a wider range, only in this way can really eliminate the inevitable language barriers in communication. It should be stressed that mastering English listening comprehension cannot expect in a short duration of time, must unremittingly hard work. As long as the repeated practice, conscientiously sum up, there is a harvest. Is the acquisition of language in communication, and communication skills are trained in practice.
\end{abstract}

\title{
Acknowledgements
}

This work is supported by Social Science Foundation of Liaoning Province (No. L15DWW005) and Bohai University Teaching Reform Project (No.BDJG15QNB002).

\section{References}

[1] Xu Wenling. The language constraints of Russian Listening [J]. Journal of PLA Foreign Languages Institute (05) (2005).

[2] Heying. Research on integration of [J]. foreign language teaching and normal teaching listening strategies. 2004 (06).

[3] Su far. On the teaching of listening learning strategies: an experimental study based on Chinese EFL Beginners [J]. modern foreign language. 2003 (01).

[4] Wang Yu. A survey on listening strategies of non English Majors in China [J]. foreign language world. 2002 (06).

[5] Li Dongmei. A review of the research on English listening comprehension in China in recent ten years [J]. foreign language world. 2002 (02). 